\title{
The Response of Drifting Buoys to Currents and Wind
}

\author{
W. Krauss, J. DengG, AND H.-H. Hinrichsen \\ Institut für Meereskunde an der Universität Kiel, Kiel, Federal Republic of Germany
}

\begin{abstract}
Two buoy types have been tested with respect to their drift performance under drogued and undrogued conditions. Additionally, forces acting on the buoys were measured directly. Quadratic drag laws have been confirmed for the drag in water and the combined drag of wind and waves. Stokes drift contributes about one half to the wind factor of 0.023 , which is obtained for undrogued buoys in the Atlantic. The forces on a windowshade drogue are given by a linear relation between force and water velocity for speeds exceeding $10 \mathrm{~cm} / \mathrm{s}$. They have been extrapolated to speeds of less than $10 \mathrm{~cm} / \mathrm{s}$ by both a linear and a quadratic relationship. Correlations between drift and wind speed in the Atlantic suggest that the linear law is a better approximation under realistic conditions. According to these measurements in the Atlantic the described buoy-drogue system with a windowshade drogue in $100-\mathrm{m}$ depth is a good current-measuring device. Slippage is negligible for wind speeds of less than $15 \mathrm{~m} / \mathrm{s}$ and is less than $2 \mathrm{~cm} / \mathrm{s}$ under gale conditions. Undrogued buoys are strongly affected by wind and cannot be used for the analysis of currents without correction, even under light winds.
\end{abstract}

\section{INTRODUCTION}

Lagrangian drift measurements are probably the oldest method of measuring ocean currents near the sea surface. For instance, drift data from ships, as collected by hydrographic offices, represent the basis of the present charts of surface currents. The ship's drift is the difference between the predicted and the actual position of the ship due to wind and wave action. Despite the fact that a ship is possibly the worst drifter, the data allowed the derivation of the large-scale circulation pattern of the world ocean.

Systematic drift measurements in the near-surface layer have been carried out over decades with drift bottles or drift cards in plastic envelopes. This method gives only the starting and final points of a trajectory. The first systematic use of remotely positioned Lagrangian buoys is due to Stommel [1954]. Since the development of techniques to locate the position of the drifter by satellites, a large number of buoys have been deployed in the ocean. In the central and northern North Atlantic the most extensive data set has been obtained by the Institut für Meereskunde, Kiel. Figure 1 depicts the 10-day averages of all trajectories obtained from 1981 to April 1988. It comprises 58,010 buoy days, each typically comprising 4-10 locations by the Argos system. This is a unique data set for studying the large-scale mean flow [Krauss, 1986] and its mesoscale variability [Krauss and Käse, 1984; Krauss and Böning, 1987], as well as tidal and inertial currents. The chart will be supplemented in the northernmost areas by 20 buoys in the Irminger Sea which were deployed in May 1988.

The buoys were released in order to study the geostrophic circulation pattern near the sea surface. For that purpose the buoys were drogued at $100-\mathrm{m}$ depth in order to reduce the influence of wind-driven Ekman currents and the associated vertical shear.

The quality of Lagrangian drift data obtained from buoys is under debate. The entire system consists of a buoy, which is exposed to wind and wave forces; a tether line on which the currents drag; and a drogue, which should minimize the near-

Copyright 1989 by the American Geophysical Union.

Paper number 88JC04035.

$0148-0227 / 89 / 88 \mathrm{JC}-04035 \$ 05.00$ surface effects and should follow the water mass as accurately as possible. This water-following capability is essential for the quality of a Lagrangian data set.

Unavoidably, owing to the permanent action of waves the buoys eventually lose the drogues, probably after a drift of half a year or longer [Richardson, 1981]. Examples of shorter lifetime are also known [Kirwan et al., 1978a]. This may also be the case in the northern part of the North Atlantic Ocean, where during the entire year severe storms can pass by with extreme wave heights. In most cases no dramatic changes can be seen in the trajectories after the loss of a drogue. The reason for that is barely understood, and systematic studies are required in order (1) to distinguish drogued from undrogued drifters and (2) to clarify whether undrogued drifters can still be used and related to the real drift at the sea surface. Drogue indicators have not been reliable enough in the past, whether based on measuring the load of the drogue or on measuring the tilt of the buoy. A reason may be that only parts of a drogue are lost or that the entire system changes its configuration and its response as a result of biofouling. Newly developed devices seem to be more promising (D. Hansen, personal communication).

To elucidate the problem, we depict two extreme cases in Figures 2 and 3, where drogue loss is obvious. Figure 2 shows the trajectory of a buoy which was deployed with drogue on April 13, 1986, in the western North Atlantic $\left(44^{\circ} 54^{\prime} \mathrm{N}\right.$, $47^{\circ} 31^{\prime} \mathrm{W}$ ), passed the Faeroe-Shetland Channel in February 1987 and followed the Norwegian Current during $2 \frac{1}{2}$ months with an average speed of $15 \mathrm{~cm} / \mathrm{s}$, which seems to be a reasonable value. In May 1987 the buoy started to drift in the opposite direction, slightly shifted toward the west. The drift against the Norwegian Current continued for more than 2 months and contradicts any other observation in that area. It was finally picked up by R/V Poseidon in November 1987. The underwater part of the buoy was entirely covered by barnacles. The buoy was undrogued.

Another example is shown in Figure 3 from the eastern subtropical gyre. Trajectories 3582, 3585, and 3586 stem from buoys which had been deployed in the western North Atlantic in August 1984 and arrived in the area under 9 months of drift. Buoys 3596, 5550, 5551, 5554, 5556, and 5559 had been launched in the area in April 1985 and show the typical drift in a current field which is composed of a mean flow and an 


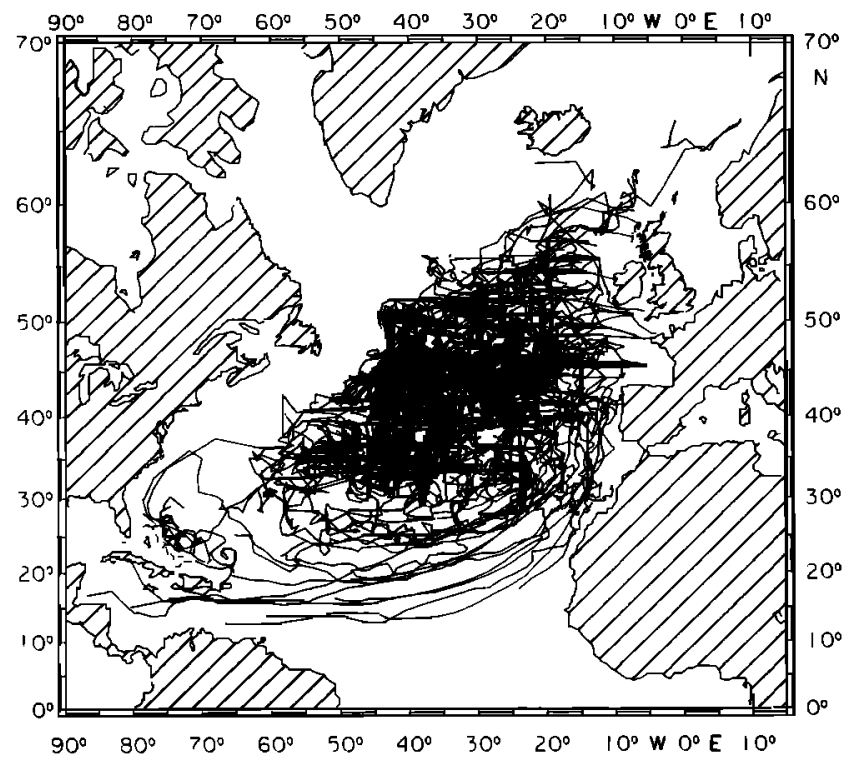

Fig. 1. Trajectories of buoys in the central and northern North Atlantic, 1981-April 1988 (10-day averages).

eddy field. Drift is shown for both sets from June 1 to the end of August 1985. Note the large difference in mean speed (Table 2a).

Many attempts have been made to get more insight into the response of Lagrangian drifters to the various forces acting on the system [Kirwan et al., 1975, 1979; McNally, 1981; Niiler et $a l ., 1987$, etc.]. One of the problems is that a large variety of buoys are used with many different shapes, ranging from circular floats to cylindrical ones. The drogue configuration may vary even more: parachutes, holey socks, windowshade drogues, and various types of crossed vane drogues are in use. Under stationary conditions, the sum of the forces $\mathbf{K}_{\boldsymbol{i}}$ acting on the different components of the system must vanish,

$$
\sum_{i} \mathbf{K}_{i}=\mathbf{0}
$$

These forces are (1) wind drag on the buoy, (2) current drag on the submerged part of the buoy, (3) nonlinear wave action, (4) drag of currents on the tether between the sea surface and the drogue (the currents may change speed and direction along the line), and drag on the drogue, if the components 1-4 pre-

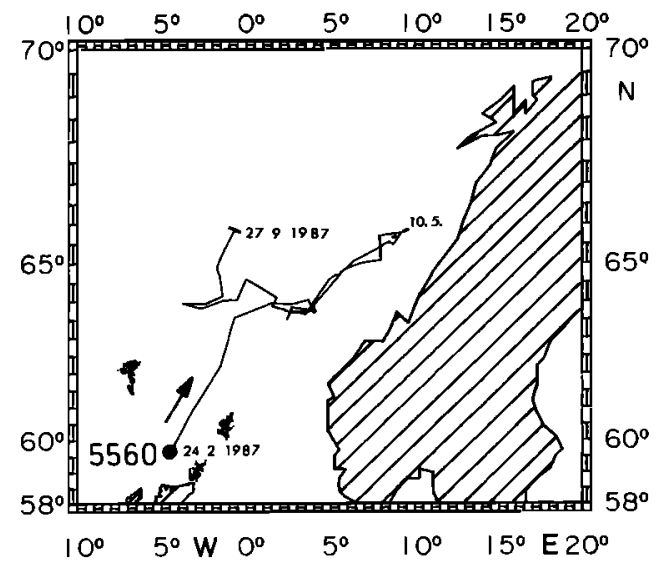

Fig. 2. Drift of buoy 5560 in the Norwegian Sea from February 24, 1987, until September 27, 1987 (5-day averages).

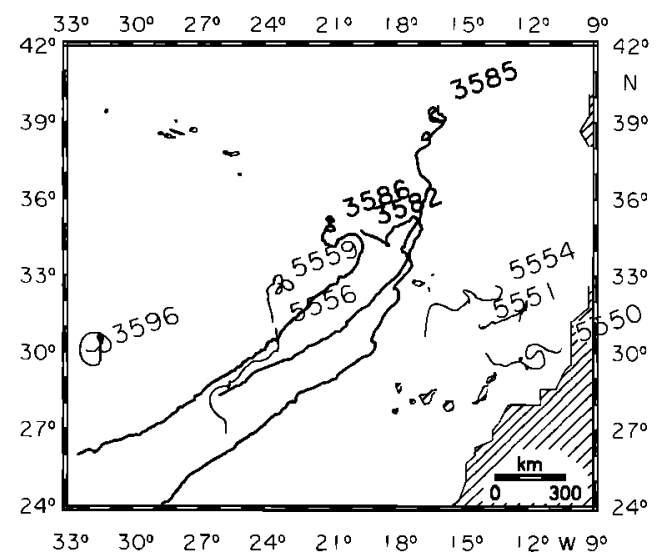

Fig. 3. Drift of buoys in the eastern subtropical gyre from June 1 to August 31,1985 . Buoys 3582,3585 , and 3586 (heavy lines) had been released in the western North Atlantic and had already drifted 9 months.

vent the drogue from drifting with the velocity of the surrounding water. These forces are generally assumed to follow a drag law of the form

$$
\mathbf{K}=\rho c F|\mathbf{v}| \mathbf{v} / 2
$$

where $\rho$ is the density of the surrounding fluid; $F$ is the cross area, which is exposed to the flow (or the entire surface); $v$ is the relative velocity; and $c$ is a drag coefficient, which has to be determined experimentally (and depends on the definition of the area $F$ ). Obviously, the ratio $\sum_{i} c_{i} F_{i} / c_{D} F_{D}$ must be small in order to obtain good drift results ( $D$ refers to drogue). Under ordinary conditions, $\mathbf{K}$ can be measured easily for models of the real system under steady flow conditions. A summary of steady-flow drag coefficients for most of the commonly used drogues is given by Vachon [1980].

If waves are present, the conditions become much more complicated, even in tanks with rather regular waves. Lange and Hühnerfuss [1978] arrived at the conclusion that the surface drift due to gravity waves agrees well with the theoretical Stokes drift velocity, if slicks are used as drift indicators. Using relatively stiff and thick floats results in drifts up to $150 \%$ higher. Under the combined effect of wind and waves, they obtained drift speed to wind speed ratios of $2.6 \%$ to $5.5 \%$ for slicks.

For floats, submersion and the configuration of the body become critical. If the drogue line slackens in the wave troughs, the buoy may surf down the front side of the wave. Furthermore, wave breaking may force the buoy to move faster than the surface water. On the other hand, high waves may reduce the wind effects if large drogues are used and the buoy is no longer able to follow the surface waves but becomes submerged under the wave crest. In this case the buoy is mainly exposed to the wind field in the wave troughs during severe storms, which may reduce the force.

Field measurements under these conditions are difficult to perform. Niiler et al. [1987] report results for wind speeds of $2-10 \mathrm{~m} / \mathrm{s}$ and wave heights of $0.3-2.2 \mathrm{~m}$. They compared drift measurements in the mixed layer with current velocities measured by two vector-averaging current meters attached to the top and the bottom of their Tristar drogues. Comparisons of trajectories of windowshade drogues in the mixed layer with progressive vector diagrams from moored current meters have been published by Richardson and Wooding [1985].

Drift measurements are more critical in the mixed layer 

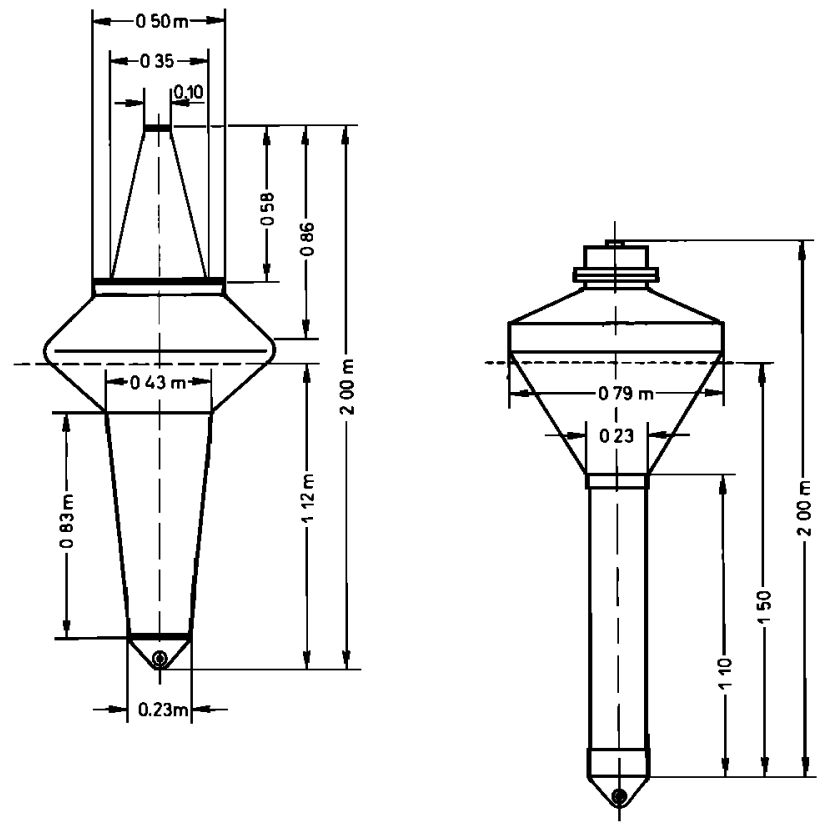

Fig. 4. Buoy configurations of the (left) Hermes and (right) Ceis buoys.

than in the layer beneath because of strong shears in the Ekman layer, which may result in kiting and lifting of the drogue. The drag on the tether is less important if the cross area of the line is small compared to the drogue area. With a drogue in 100-m depth the tether line may be exposed to a complicated current profile [Weller and Halpern, 1983; Weller et al., 1985; McNally and White, 1985]. Inertial waves may introduce additional effects [White, 1986]. However, the main slippage results from the action at the sea surface, which makes it difficult to model the response of the system.

The applicability of quadratic drag laws is questionable. Kirwan et al. [1978b] tried to correct the trajectories of undrogued buoys for wind drag. It turned out that the corrections due to the quadratic law, using real wind data of the area, were unrealistically large for high winds and that the uncorrected velocities seemed to be a better representation of the real velocities than did corrected ones.

In the present article we make an attempt to determine the forces acting on the drifter system which we use in the North Atlantic (section 2). As measurements of the type described in the subsequent sections cannot be performed in the deep ocean, we chose a shallow area in the western Baltic Sea for

TABLE 1. Specifications of the Hermes and the Ceis buoys

\begin{tabular}{|c|c|c|}
\hline Buoy Data & Hermes & Ceis \\
\hline Length, m & 2.00 & 2.10 \\
\hline Maximum diameter, $\mathbf{m}$ & 0.86 & 0.80 \\
\hline Submerged part with drogue, $m$ & 1.12 & 1.50 \\
\hline Center of gravity, $\mathrm{m}^{*}$ & 0.28 & 0.75 \\
\hline Weight in air, kg & 74 & 90 \\
\hline Volume, $\mathrm{m}^{3}$ & 0.27 & 0.22 \\
\hline Total buoyancy, $\mathrm{N}$ & 2720 & 2200 \\
\hline Buoyancy without drogue, $\mathbf{N}$ & 1990 & 1300 \\
\hline Buoyancy with drogue, $\mathrm{N}$ & 1540 & 850 \\
\hline Cross area above sea surface, $\mathrm{m}^{2}$ & 0.41 & 0.21 \\
\hline Cross area below sea surface, $\mathrm{m}^{2}$ & 0.43 & 0.45 \\
\hline Cross area of drogue, $\mathrm{m}^{2}$ & 15.60 & 15.60 \\
\hline
\end{tabular}

*Below sea surface. the experiments. This may be considered as a compromise between artificial tank conditions and the deep ocean. In sections 3 and 4 we describe the test area and discuss the results. In sections 5 and 6 we try to relate them to results from data in the North Atlantic.

\section{Buoy-Drogue Configuration}

During 1981-1987, two types of buoys have been used in the North Atlantic, which are named according to the manufacturer: the Hermes buoy and the Ceis buoy. They are depicted in Figure 4, their technical specifications are listed in Table 1 , assuming a density of $1027 \mathrm{~kg} / \mathrm{m}^{3}$ for the buoyancy forces. The buoys are similar in shape, but the Ceis buoy is heavier and more deeply submerged than the Hermes buoy, and it has only hall of the net buoyancy if drogued. Thus the Hermes buoy is more exposed to wind, whereas the Ceis buoy is more exposed to waves and currents. The main difference in shape is the more conical form of the Hermes buoy both above and below sea surface. Undrogued Hermes buoys are inclined by about $50^{\circ}$ against the vertical, whereas Ceis buoys remain vertical. Compared with the drogued case, where the wind has to force a vertical cylinder horizontally through the water, the submerged part of the undrogued buoy more closely resembles a ship's hull, even if of complicated form. We may expect that in this undrogued case the buoy feels less resistance in the water and is more exposed to the wind and the Stokes drift. The tether line, which connects the buoy to the drogue, is a nylon rope (Polyamid) of 14-mm diameter. It is linked to both ends of the upper bar of the drogue. The windowshade drogue is made of canvas with iron bars at top and bottom. Its size is $2.80 \times 6.00 \mathrm{~m}$. The upper bar has a weight of $18.5 \mathrm{~kg}$, the lower one $27.2 \mathrm{~kg}$, and the canvas $10 \mathrm{~kg}$. The entire drogue (including shackles, etc.) has a weight of about $60 \mathrm{~kg}$. The two horizontal bars are connected at both ends by 14-mm nylon rope, which carries the lower bar. Its length is $5.5 \mathrm{~m}$, which allows the drogue to bow in the current. Experiments show that the sail is oriented perpendicular to the current, yielding a cross area of $15.6 \mathrm{~m}^{2}$ including the tether ropes. The entire system is shown in Figure 5. The following forces are acting on the system: (1) $\mathbf{K}_{A}$, wind force on the buoy; (2) $\mathbf{K}_{\Sigma}$, combined wind and wave forces on the buoy, including Stokes drift; (3) $K_{W}$, current forces on the submerged part of the buoy; (4) $K_{R}$, current drag on the tether rope (the current may be decomposed into a geostrophic component, which is to be

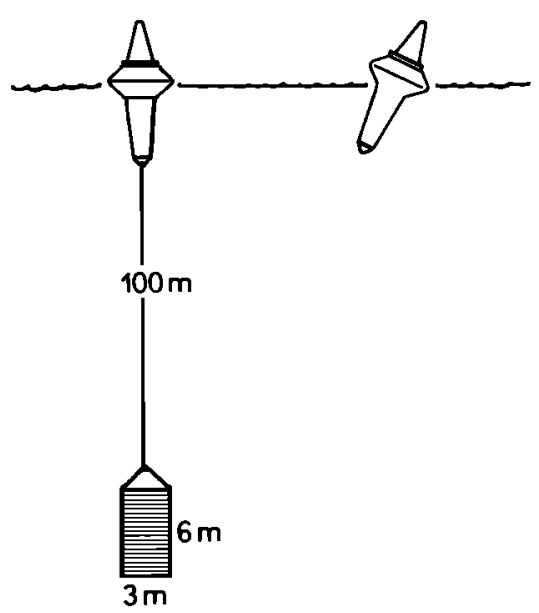

Fig. 5. The buoy system (with and without drogue). 
measured at $100 \mathrm{~m}$ depth, and an ageostrophic component); and (5) $\mathbf{K}_{D}$, current drag on the drogue (note from Table 1 that the cross-area ratios between half of the buoy (that part which is in air or water) and the drogue is in both cases approximately $3: 100$ ). On average,

$$
\mathbf{K}_{\Sigma}+\mathbf{K}_{W}+\mathbf{K}_{R}+\mathbf{K}_{\boldsymbol{D}}=\mathbf{0}
$$

must hold.

\section{The Test Area}

For logistic reasons, Kiel Bay and the Fehmarn Belt have been chosen for the test. Kiel Bay is a shallow area of about 18- to 20-m depth. The Fehmarn Belt is one of the main connections between the Baltic Sea and the North Sea. The currents there are prescribed by topography and coastal configuration. The usual current system consists of outflow from the Baltic Sea in the upper layer and inflow of more saline water in the deeper layers. The average depth in the channel, where the maximum currents are observed, is $28 \mathrm{~m}$.

Current speed depends strongly on the large-scale wind fields and the resultant sea level difference between the Baltic and the North Sea. This large-scale difference in sea level controls the flow, which is little influenced by local wind. In Kiel Bay, currents are weak and variable.

The width of Kiel Bay is about $50 \mathrm{~km}$, and that of the Fehmarn Belt is $20 \mathrm{~km}$. Measurements were carried out with R/V Poseidon between November 24 and December 3, 1987, under wind speeds which varied from 0 to $20 \mathrm{~m} / \mathrm{s}$. Wind was routinely measured (averages of $4 \mathrm{~min}$ ) at a height of $22.5 \mathrm{~m}$. Tests have shown that the speed at this level is not significantly different from that at $10 \mathrm{~m}$ but decreases by $2 \mathrm{~m} / \mathrm{s}$ between $10 \mathrm{~m}$ and $1 \mathrm{~m}$ above sea surface.

Currents between $1-\mathrm{m}$ and $6-\mathrm{m}$ depth were measured with a small drift buoy, which was designed to have a very small drag area ratio between buoy and drogue. The buoy is a double cone of $30-\mathrm{cm}$ diameter and a total height of $60 \mathrm{~cm}$, being hall exposed to the wind and half to the water. Its buoyancy is 14.5 $\mathrm{kg}$. The tether between buoy and drogue had a length of 60 $\mathrm{cm}$ and an additional weight of $5 \mathrm{~kg}$. The drogue was a biplanar crossed vane of $1 \mathrm{~m} \times 4.75 \mathrm{~m}$ canvas, stabilized by a weight of $2.5 \mathrm{~kg}$. The cross-section areas of buoy and drogue have a ratio of $1: 50$. They have proven to be very good indicators of the real current in that depth. Location was by Decca with an accuracy of $\pm 20 \mathrm{~m}$. Wave height was measured with a wave rider buoy, if necessary.

The small buoy has been designed in connection with dye measurements [Krauss, 1965]. During winds of up to $8 \mathrm{~m} / \mathrm{s}$ a solution of rhodamine was released around the drifter, and the motion of the buoy was observed with respect to the dye. In the homogenous surface layer without vertical shear, kiting has not been observed, and the accuracy of the velocity measurements was in the range of $\pm 1 \mathrm{~cm} / \mathrm{s}$.

The experiments described in the subsequent sections have been carried out during November-December, when the upper $10 \mathrm{~m}$ of the water column are well mixed in Kiel Bay. As was mentioned previously, the currents are steered by topography and coastal configuration and are driven by the large-scale pressure difference. Ekman spirals are not observed in the area. Vertical shear in the upper meters, therefore, results only from Stokes drift at high wind velocities. The performance of the small drifter at high wind speeds may be seen directly from Figure 8, which displays the velocity vector $\mathrm{v}$ of the small buoy and those of two undrogued buoys, which are

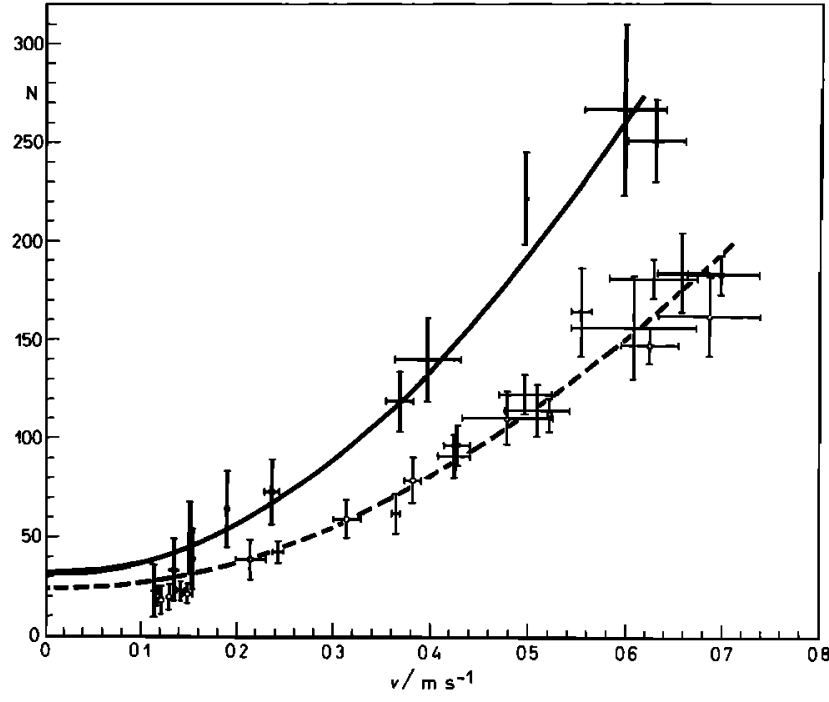

Fig. 6. Forces on the buoy (in newtons) as function of current velocity (meters per second).

exposed to wind and current $\left(\mathbf{v}_{D_{1}}\right.$ and $\left.\mathbf{v}_{D_{11}}\right)$. The wind blew in the direction of $249^{\circ}$, and the difference vectors have directions of $249^{\circ}$ and $249.5^{\circ}$, which is consistent with the accuracy given above (a deviation of $1^{\circ}$ would correspond to $1 \mathrm{~cm} / \mathrm{s}$ in this case).

The main difference between the test area and the ocean near the sea surface is the limited fetch in Kiel Bay and, consequently, a different sea state. In the center of Kiel Bay, fetch is limited to $15 \mathrm{~nm}$. In November the most frequent wave period is 3-4 s, and the significant wave height $H_{1 / 3}$ takes values less than $1.5 \mathrm{~m}$ in $96 \%$ of all cases. A fully developed sea exists only for wind speed of less than $6-8 \mathrm{~m} / \mathrm{s}$. This has consequences for the Stokes drift and yields different drift characteristics for high wind speed. Nevertheless, the data obtained there give very useful results, if combined with those from the Atlantic Ocean.

\section{Results from Kiel Bay}

The measurements consisted of two types. (1) Forces on buoy and drogue were measured from the anchored ship either in the currents of the Fehmarn Belt or by towing the body towards the ship with constant speed. If required, the ship was anchored at bow and stern in order to guarantee a stable platform. (2) Drift measurements of undrogued buoys were made under various wind conditions. Positioning was by Decca.

\subsection{Forces Acting on the Buoy \\ Due to Currents}

The ship was anchored in different parts of the Kiel Bay where currents were weak. The buoy was released and then towed toward the ship by an electric winch with various speeds. A thin rope was used for towing. Forces were measured with a dynamometer; the currents at the location were measured simultaneously with the small drifter mentioned previously.

The results are displayed in Figure 6. Each data point includes typically 10-30 measurements of force and four of current speed, yielding the error bars in the figure. As data of the Ceis buoys are not essentially different from those of Hermes buoys, data from both types are included in the figure (the 


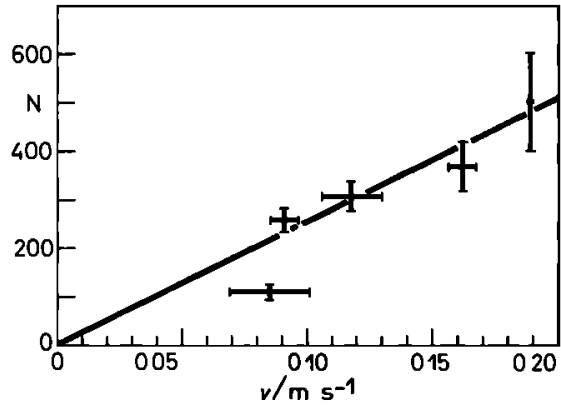

F1g. 7. Forces on the drogue.

drag on the Hermes buoy is slightly smaller). The top (solid) curve was obtained with a buoy where the load of the drogue was simulated by a weight of $50 \mathrm{~kg}$ directly at the bottom of the buoy. Thus this buoy stands vertically in the water as under drogue conditions. The bottom (dashed) curve results from buoys without additional weight, like undrogued buoys. They were inclined to the vertical by about $50^{\circ}$ owing to the missing weight at the bottom. Solid and open circles indicate buoys with an additional frame. They are slightly more exposed to wind.

Quadratic laws are obtained in both cases for velocities which exceed $0.2 \mathrm{~m} / \mathrm{s}$. For values of less than $0.2 \mathrm{~m} / \mathrm{s}$ a linear approximation would be possible in order to reduce the force to zero at zero velocity. However, it is more likely that the curves are offset by an additive force due to the movements of the ship. The resultant relations are

$$
K_{W}=23.5+346 v^{2}
$$

for the buoy without weight (inclined to the vertical) and

$$
K_{W}=31.4+630 v^{2}
$$

for buoys with weight (vertical position).

All forces are given in newtons $(\mathbf{N})$, and speeds are in meters per second. It should be mentioned that these measurements were made under light wind conditions and therefore do not include wave and wind effects. For further considerations we neglect the offset in (4) and (5) and use

$$
\begin{aligned}
& K_{W}=350 v^{2} \\
& K_{W}=630 v^{2}
\end{aligned}
$$

for buoys without and with weight, respectively. The larger coefficient for the buoy with weight results from the fact that the buoy is more deeply submerged in the water.

\subsection{Forces Acting on the Drogue}

The ship was anchored in different parts of the Fehmarn Belt in order to measure the forces exerted on the drogue under various current conditions. In order to prevent the drogue from bowing, the drogue was stiffened mechanically by a frame. The windowshade drogue was kept at a distance of $50 \mathrm{~m}$ from the ship and in a vertical position. It could take any orientation to the current vector. It turned out that the shade was always oriented perpendicular to the current with little variations. The results are depicted in Figure 7 and can be described by a linear relationship. The lowest data point $(120 \mathrm{~N})$ is based on very few measurements and may be erroneous. If it is omitted, we obtain $K_{D}=43+2270 v$; otherwise, $K=-60+2890 v$. In Figure 7 the straight line is given by the average increase of $K_{D}$ with $v$,

$$
K_{D}=2580 v \quad v>0.08 \mathrm{~m} / \mathrm{s}
$$

and the mean offset of -8.5 has been neglected.

During the cruise it was not possible to extend the measurements into the range $v<0.09 \mathrm{~m} / \mathrm{s}$, which is required for the interpolation of the drift performance of the system. In Figure 7 the linear law is supposed to hold in the entire range $0<v<20 \mathrm{~cm} / \mathrm{s}$.

As was pointed out by one of the reviewers, this may be questionable. Laboratory experiments indicate that the drag coeflicient is dependent on the Reynolds number, which yields a quadratic law for small velocities and a linear one for large velocities. Whether or not such a relation also holds in the ocean is unknown. For comparsion we additionally used the quadratic law. According to the laboratory results of Vachon [1980], the linear law should be applied if $K_{D} / W_{D}$ exceeds 0.5 , where $W_{D}$ is the weight of the drogue. In the present case this corresponds to $K_{D}=200 \mathrm{~N}$ or $v \approx 0.08 \mathrm{~m} / \mathrm{s}$. If we fit a quadratic law through $K_{D}=200, v=0.08$, we obtain

$$
K_{D}=31,250 v^{2}
$$

which results in a considerable reduction of the drag for small velocities. It will be shown in sections 5 and 6 that this is not consistent with observations in the Atlantic.

In order to get an insight into the behavior of the system under large waves, the drogue was lifted vertically with speeds between 0.05 and $0.1 \mathrm{~m} / \mathrm{s}$. Forces of about $2500 \mathrm{~N}$ were measured due to the drag. As the buoys have a net buoyancy of only $1540 \mathrm{~N}$ (850 $\mathrm{N}$ in case of the Ceis buoys), the buoy cannot lift the drogue in heavy sea, where orbital velocities of several meters per second occur. Instead, the buoy becomes submerged under the wave crests if stretching of the rope cannot balance the difference between wave crest and trough. With a stretch rate of $5 \%$, this will occur for waves higher than about $10 \mathrm{~m}$, if the drogue remains in $100-\mathrm{m}$ depth relative to the undisturbed surface.

\subsection{Direct Wind Influence}

The force on the part of the buoy that is directly exposed to the wind is difficult to determine, because of simultaneous wave action. However, as a fully developed sea cannot exist in Kiel Bay for wind speeds beyond $8 \mathrm{~m} / \mathrm{s}$, force measurements at high wind speed show mainly the direct wind effect.

During the cruise, just one such situation occurred. For a wind speed of $14 \pm 0.9 \mathrm{~m} / \mathrm{s}$ we measured $30 \pm 9 \mathrm{~N}$. This would suggest a relation

$$
K_{A}=0.15 W^{2}
$$

where $W$ is wind speed. However, we will not make use of that.

\subsection{The Combined Influence of Wind} and Waves

The drift of a body at the surface depends on the wind force $K_{a}$; the frictional force $K_{W}$, which results from moving the body through the water; and the displacement of the body by the surface currents. Measurements in the past gave a linear relationship between drift velocity and wind speed at $10 \mathrm{~m}$, $v=k W$, without any significant deflection of the drift direction from the wind direction. Here, $k$ is called the wind factor and depends strongly on the thickness of the layer represented 


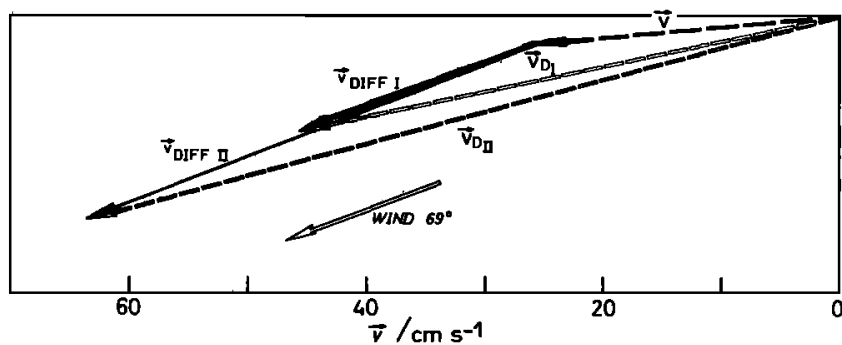

Fig. 8. Observed velocity $v$ in $1-$ to $6-m$ depth, drift velocities $v_{D_{1}}$ (with weight) and $v_{D_{11}}$ (without weight), and velocities $v_{D_{\text {iff }}}$ and $v_{\text {Diff }_{1}}$ due to the combined wind and wave action (wind from $69^{\circ}$ ).

by the drift body in the water. Values varying between 1 and 4.3 have been reported [Tomczak, 1964], with the highest values for drift cards and oil films at the surface.

Surface currents may be separated into Stokes drift and other currents at the sea surface, like tidal currents, geostrohic currents etc. The Stokes drift is due to waves of finite amplitude and is given by

$$
\left\langle v_{s}\right\rangle=\frac{a^{2} \omega \kappa}{2 \sinh ^{2} \kappa H} \cosh 2 \kappa(z+H)
$$

where $\omega$ and $\kappa$ are frequency and wave number, respectively, $a$ is amplitude, and $H$ is water depth. For a fully developed sea, G. Neumann (cited by Dietrich et al. [1980, Table 8.02]) has tabulated corresponding values of mean wave period $\tau_{m}$, mean wave length $\lambda_{m}$, and mean wave height $h_{m}$ as a function of wind speed. From this table we derive the following relations:

$$
\tau_{m}=0.55 \mathrm{~W} \quad \lambda_{m}=0.32 \mathrm{~W}^{2} \quad h_{m}=0.02 \mathrm{~W}^{2}
$$

Substitution into (9) yields

$$
\left\langle v_{s}\right\rangle=0.011 \mathrm{~W}
$$

a direct proportionality between drift and wind velocity at the surface in deep water. As outlined in section 3, Kiel Bay is a limited area where a fully developed sea can occur only for wind velocities of less than $6-8 \mathrm{~m} / \mathrm{s}$. Furthermore, the water depth is about $20 \mathrm{~m}$, which doubles $\left\langle v_{s}\right\rangle$ near the surface owing to the depth factor in (9).

Under "combined influence of wind and waves" we summarize the resulting drift velocity of an undrogued buoy due to the direct wind influence, the drag due to (6), the Stokes velocity $v_{s}$, and the direct wave action (surfing etc.). Drift measurements have been carried out in Kiel Bay. Velocity was measured again with the small drifter. Buoys with and without 50 kg weight were used. The location was by Decca. An example of the combined influence of wind and waves is shown in Figure 8. The wind was $17 \mathrm{~m} / \mathrm{s}$ from $69^{\circ} ; v_{D_{1}}$ and $v_{D_{11}}$ are the drift velocities of the buoy with $50 \mathrm{~kg}$ weight and without weight, respectively, and $\mathbf{v}_{\text {Diff, }}$ and $\mathbf{v}_{\text {Dirf, }}$ are the corresponding difference vectors due to wind and waves, which have the same direction. This shows the large influence of wind and waves on undrogued buoys. It further elucidates that the drift velocity of these buoys is strongly dependent on the submersion of the buoy.

If we subtract the current velocity (measured with the small buoy) from the drift velocity, we obtain the resultant velocity due to wind and waves, $\mathbf{v}_{\text {Diff }}$, as function of wind speed $W$. This is plotted in Figure 9. The dots refer to buoys without weight, the circles to those with $50 \mathrm{~kg}$ weight. The error bars result from the variability of the wind speed during the measurements, which lasted typically 3-4 hours.

The data for wind speeds of less than $10 \mathrm{~m} / \mathrm{s}$ yield the relations

$$
v=0.053 W
$$

for unweighted buoys and

$$
v=0.037 \mathrm{~W}
$$

for buoys with $50 \mathrm{~kg}$ weight. The measurements at $17-\mathrm{m} / \mathrm{s}$ wind velocity gave drift speeds of 0.41 and $0.21 \mathrm{~m} / \mathrm{s}$ for these buoys. As outlined above, the sea is not developed at high wind speeds. We therefore added the Stokes velocities in shallow water $(0.022 \mathrm{~W})$ to the measured data and incorporated these corrected values into Figure 9 for comparison. As was already mentioned in connection with Figure 8, submersion of an undrogued body has a large influence on the drift speed.

\subsection{Discussion of the Results in Kiel Bay}

Force measurements are difficult to achieve on a ship and may yield large error bars. However, we believe that shipboard measurements are more representative for real conditions than are measurements made under the artificial conditions of a wave tank. The measurements have been made with R/V Poseidon (1050 tons), which was a rather stable platform if anchored at bow and stern. Unavoidably, these measurements can be made only in shallow water and must be transferred to oceanic conditions with a different sea state. As will be shown in section 5 , this yields a reduction of the wind factor under oceanic conditions, whereas the Stokes drift is increased in Kiel Bay by the depth factor in (9).

Furthermore, the buoys may be submerged more often in heavy seas in the Atlantic than in Kiel Bay, which would further reduce the direct influence of the wind. Nevertheless, we can deduce from these results the main forces acting on a drogued or undrogued system. For wind speeds of up to 17 $\mathrm{m} / \mathrm{s}$ we have shown that undrogued buoys are strongly affected by direct wind and wave action. This holds both for buoys floating at the sea surface and for buoys which are drifting under similar conditions as if they were drogued. Buoys that have lost their drogues may respond in any way within the range described by the two cases, depending on fouling and other factors.

The drag law for resistance in water (equation (6)) corresponds to the expected quadratic law, and the velocity range from 0 to $0.7 \mathrm{~m} / \mathrm{s}$ covers the entire range which may occur in the ocean as velocity difference between drogue depth and sea

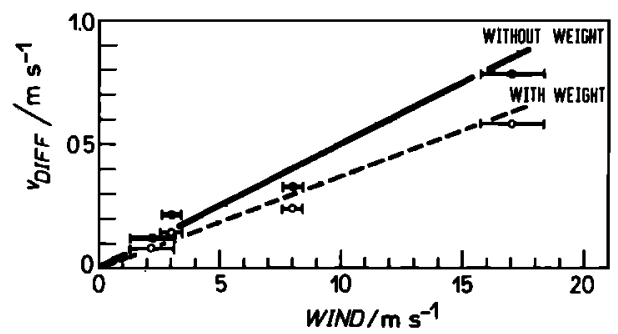

Fig. 9. Drift velocities $v_{\text {pirr }}$ as function of wind speed. Solid circles correspond to buoys without weight, and open circles correspond to buoys with $50 \mathrm{~kg}$ weight. Solid lines indicate least squares approximations in the range $W<10 \mathrm{~m} / \mathrm{s}$. 


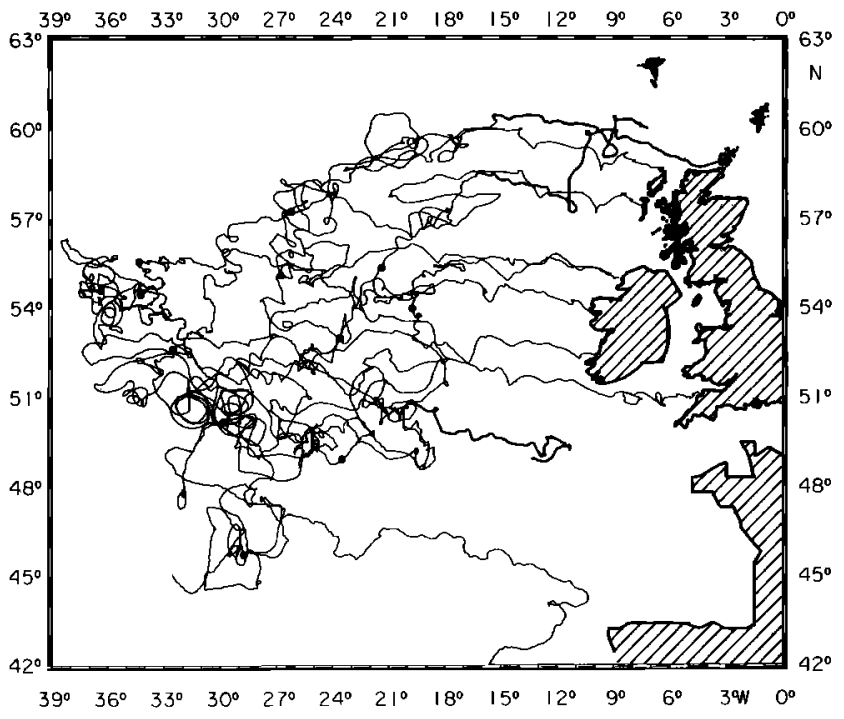

Fig. $10 a$
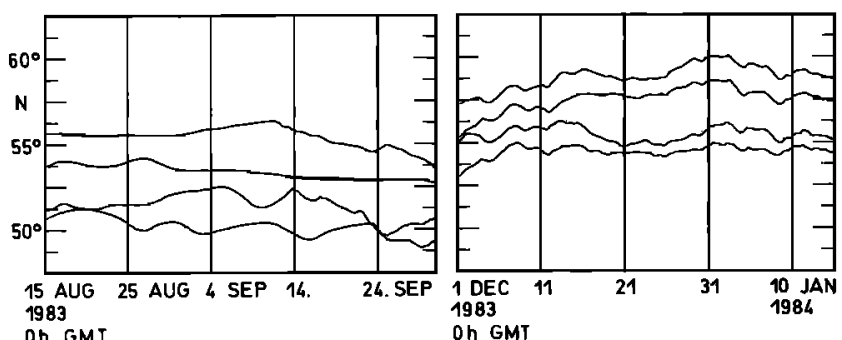

Fig. $10 b$

Fig. 10. (a) Trajectories of 11 buoys in the eastern North Atlantic in 1983, drifting from west to east. Dot marks December 1. (b) Meridional displacement of four buoys of the data set of Figure 10a during (left) August-September 1983 and (right) December-January 1984.

surface. For the forces on the drogue we obtain a linear relationship between force and current speed for $v>0.08 \mathrm{~m} / \mathrm{s}$, which is far beyond the range of interest. The ratio of drogue surface to buoy surface must be chosen such that only a few $\mathrm{cm} / \mathrm{s}$ occur relative to the drogue.

The main results of these measurements are as follows.

1. A relative velocity of $10 \mathrm{~cm} / \mathrm{s}$ exerts a force of 3-6 N on a buoy of the type described in section 2 . The value depends on the submersion of the buoy.

2. The force on a windowshade drogue of about $15 \mathrm{~m}^{2}$ amounts to about $25 \mathrm{~N}$ if the slippage is $1 \mathrm{~cm} / \mathrm{s}$ and the linear law is extended to the range $v<8 \mathrm{~cm} / \mathrm{s}$. In the case of the quadratic law the force would be only $3 \mathrm{~N}$, and the system would be under strong wave and wind influence.

3. The direct influence of the wind is important. For a moderate wind speed of $10 \mathrm{~m} / \mathrm{s}, 15 \mathrm{~N}$ are acting on the buoy. Wind speed in all cases refers to measurements at 22-m height. Comparisons have shown that the value at $10 \mathrm{~m}$ is not signifcantly different from that.

4. The combined influence of wind and waves yields drift velocities of $0.4-0.5 \mathrm{~m} / \mathrm{s}$ for undrogued buoys at a wind speed of $10 \mathrm{~m} / \mathrm{s}$ depending on the submersion of the buoy. Thus data from undrogued buoys of the type described require a very detailed knowledge of the wind field and the submersion, in order for reliable current fields to be derived from their drift.

\section{Drift Velocities of Undrogued Buoys in the Atlantic OCEan}

In order to study the influence of wind and waves on drogued and undrogued buoys in the Atlantic, we use two data sets which clearly show that some of the buoys lost their drogues. The first set is shown in Figure 3; the second set is shown in Figure 10a. In Figure 10a, December 1 on each trajectory is marked by a dot. A detailed study shows marked differences between the trajectories before and after this date. Exceptions are the three trajectories given by heavy lines. Figure $10 b$ depicts the meridional displacement of four buoys over a period of approximately 1.5 months in AugustSeptember (left) and December-January (right). Whereas the displacements are obviously uncorrelated during the first period, the excursions occur simultaneously during the second one. Such simultaneous displacements in an area which extends $5^{\circ}$ in latitude can only result from large-scale wind eflects. Inspection of the corresponding weather maps showed severe westerly storms during December 1983, which extended over the entire northeastern North Atlantic. The average mean zonal drift speed of these four buoys increased from 3.2 $\mathrm{cm} / \mathrm{s}$ during the first period to $24.4 \mathrm{~cm} / \mathrm{s}$ during the second one. This further supports our conclusion because mean velocities at $55^{\circ} \mathrm{N}$ decrease from the central North Atlantic (positions in August) toward the eastern North Atlantic [Krauss, 1986].

In Tables $2 a$ and $2 b$ we summarize some statistical parameters of both data sets. Although no definite proof can be given, we refer to the subsets as drogued and undrogued buoys, respectively.

In the subtropical eastern Atlantic (Table 2a), undrogued buoys show mean drift speeds of $31 \mathrm{~cm} / \mathrm{s}$ and speed variances of $170 \mathrm{~cm}^{2} / \mathrm{s}^{2}$. The corresponding values of drogued buoys in that area are $9 \mathrm{~cm} / \mathrm{s}$ and $24 \mathrm{~cm}^{2} / \mathrm{s}^{2}$. Thus speed of undrogued buoys is 3.6 times larger and variance is 7.0 times larger than for drogued buoys. Acceleration differs by a factor of 1.7 , and its variance differs by a factor of 3.6.

West of Ireland during winter 1983-1984 the situation is similar. Speed and its variance differ by factors of 2.1 and 3.6 , respectively. The corresponding factors for acceleration and its variance are 1.4 and 2.5 . The strong increase in variance seems to be a good indication of wind effects.

In order to elucidate the relation between drift speed and wind speed, daily averages of the drift speed have been computed and compared with wind speed in the area of each buoy. Wind speed was taken from daily weather maps at 0000 UT. The nearest ship observations were used and extrapolated to the buoy position according to the pressure field. This rather crude method turned out to be accurate enough to derive a relation. The data have been grouped into classes; each class interval has a width of 5 knots $(2.57 \mathrm{~m} / \mathrm{s})$ as listed in Table 3 and plotted in Figure 11.

Figure $11 a$ depicts the relation between drift speed and wind speed for the eastern subtropical North Atlantic. Undrogued buoys yield the relation (in meters per second)

$$
v=0.15+0.021 W
$$

where the correlation coefficient is $r=0.92$.

Drogued buoys show no wind dependency; the formal relation is

$$
v=0.08-0.0008 \mathrm{~W}
$$

with $r=-0.58$. We interpret the mean values of 0.15 and 
TABLE 2a. Statistical Parameters of Buoys Assumed to Be Drogued and Undrouged During June 1 to August 30 in the Subtropical Atlantic

\begin{tabular}{ccccc}
\hline Buoy & $\begin{array}{c}\text { Mean speed }|v|, \\
\mathrm{cm} / \mathrm{s}\end{array}$ & $\begin{array}{l}\text { Var }|v|, \\
\mathrm{cm}^{2} / \mathrm{s}^{2}\end{array}$ & $\begin{array}{c}\text { Acceleration }|a|, \\
\mathrm{cm} / \mathrm{s}^{2} \times 10^{-4}\end{array}$ & $\begin{array}{c}\text { Var }|a|,(\mathrm{cm} / \\
\left.\mathrm{s}^{2}\right)^{2} \times 10^{-8}\end{array}$ \\
\hline & & & \\
3582 & 35.9 & 172.8 & & 21.3 \\
3585 & 28.2 & 166.6 & 6.9 & 17.1 \\
3586 & 28.9 & 169.5 & 6.6 & 33.7 \\
Mean & 31.0 & 169.6 & 7.9 & 24.0 \\
& & & 7.1 & \\
3596 & 10.4 & 44.4 & & 9.8 \\
5550 & 10.5 & 26.9 & 4.6 & 8.9 \\
5551 & 6.8 & 12.4 & 4.9 & 4.7 \\
5554 & 7.8 & 30.0 & 4.5 & 4.4 \\
5556 & 9.4 & 19.0 & 3.5 & 3.8 \\
5559 & 7.5 & 13.7 & 3.5 & 6.7 \\
Mean & 8.7 & 24.4 & 3.3 & \\
\hline
\end{tabular}

$0.08 \mathrm{~m} / \mathrm{s}$ in (13) and (14) as mean drift velocities at zero or 100 $\mathrm{m}$, respectively, due to local currents at the average position of the buoys. The dependency between drift speed and wind speed for undrogued buoys is then

$$
v=0.021 W
$$

West of Ireland (Figure $11 b$ ) the relations are

$$
v=0.14+0.025 W \quad r=0.97
$$

for undrogued buoys and

$$
v=0.12+0.0035 W \quad r=0.63
$$

for drogued ones, yielding

$$
v=0.025 \mathrm{~W}
$$

This increase in speed of undrogued buoys with increasing wind speed is remarkably similar in both areas and highly significant. It amounts to about double the Stokes drift, indicating that wind and waves are equally important for the drift.

Relation (18) also indicates a small influence of wind on drogued buoys, but correlation is weak $(r=0.63)$. This results mainly from the data at wind speeds of 18 and $21 \mathrm{~m} / \mathrm{s}$, which have the highest variance. If we omit these points, the relation is $v=0.13+0.0016 \mathrm{~W}$, and $r=0.5$. With wind speeds of 20 $\mathrm{m} / \mathrm{s}$ (strong gale) we then would have a slippage of $3 \mathrm{~cm} / \mathrm{s}$.
From these measurements we conclude that the use of a quadratic law for the drogue forces at low velocities is not appropriate. The increase of drift speed of undrogued buoys as a function of wind speed in the Atlantic is in good agreement with the results from Kiel Bay. In the Atlantic we have a wind factor of 0.023 on average, to which the Stokes drift contributes 0.011 , leaving 0.012 for the wind. In Kiel Bay, shallow water effects double the Stokes drift to 0.022. Adding the wind effect of 0.012 yields 0.034 , which is very close to the value 0.037 of the undrogued buoy with $50 \mathrm{~kg}$ weight. All buoys recovered after several months of drift in the Atlantic were covered by barnacles on the submerged part of the buoy, which would have increased friction in water and caused additional submersion. The reduction of drift velocity in the Atlantic compared with Kiel Bay is therefore not unexpected.

We finally mention the large error bars in Figure 11. Part of them may result from the wind data, if the observations from midnight are not representative for the entire day (as is to be expected especially in mid and high latitudes). Another reason may be the rather crude method of extrapolation, as mentioned above. Furthermore, different submersion of the buoys may influence the results. We presently use the wind data of the European Centre for Medium Range Weather Forecasts for a detailed analysis in order to separate buoys with drogues from undrogued ones. The first results fully support the above conclusions: drogued buoys show no significant relation be-

TABLE $2 b$. Statistical Parameters of Buoys Assumed to Be Drogued and Undrouged During December 1, 1983, to February 28, 1984, West of Ireland

\begin{tabular}{rcccc}
\hline Buoy & $\begin{array}{c}\text { Mean speed }|v|, \\
\mathrm{cm} / \mathrm{s}\end{array}$ & $\begin{array}{c}\text { Var }|v|, \\
\mathrm{cm}^{2} / \mathrm{s}^{2}\end{array}$ & $\begin{array}{c}\text { Acceleration }|a|, \\
\mathrm{cm} / \mathrm{s}^{2} \times 10^{-4}\end{array}$ & $\begin{array}{c}\text { Var }|a|,(\mathrm{cm} / \\
\left.\mathrm{s}^{2}\right)^{2} \times 10^{-8}\end{array}$ \\
\hline & $\begin{array}{c}\text { Undrogued } \\
3560\end{array}$ & 717.4 & & \\
3563 & 56.5 & 766.5 & 16.2 & 171.1 \\
3564 & 22.4 & 535.0 & 8.6 & 105.4 \\
3566 & 52.3 & 946.6 & 14.5 & 133.5 \\
3567 & 46.0 & 302.6 & 13.0 & 54.8 \\
3569 & 32.4 & 1019.0 & 11.6 & 122.7 \\
3572 & 28.1 & 692.8 & 7.4 & 130.7 \\
3575 & 55.6 & 258.9 & 16.2 & 110.2 \\
Mean & 34.8 & 654.9 & 9.5 & \\
& 41.4 & & 12.1 & 28.4 \\
3561 & & 189.3 & & 30.0 \\
3562 & 18.8 & 64.9 & 8.6 & 33.7 \\
3671 & 14.7 & 287.1 & 9.5 & 30.7 \\
Mean & 25.4 & 180.4 & 9.2 & \\
\hline
\end{tabular}


TABLE 3. Number of Daily Data Points (Drift Speed) in 5-Knot Intervals of Wind Speed

\begin{tabular}{|c|c|c|c|c|c|c|c|c|c|c|}
\hline & \multicolumn{10}{|c|}{ Wind Speed, knots } \\
\hline & 0 & 5 & 10 & 15 & 20 & 25 & 30 & 35 & 40 & 45 \\
\hline \multicolumn{11}{|c|}{ Subtropics } \\
\hline Undrogued & 11 & $\cdots$ & 111 & 84 & 44 & 7 & $\cdots$ & $\cdots$ & $\cdots$ & \\
\hline Drogued & 40 & 10 & 223 & 129 & 80 & 19 & $\cdots$ & $\cdots$ & $\cdots$ & \\
\hline \multicolumn{11}{|c|}{ West of Ireland } \\
\hline Undrogued & $\cdots$ & $\cdots$ & 52 & 47 & 94 & 68 & 78 & 43 & 17 & 8 \\
\hline Drogued & $\cdots$ & $\cdots$ & 21 & 36 & 47 & 36 & 57 & 29 & 26 & 4 \\
\hline
\end{tabular}

One knot is equal to $0.514 \mathrm{~m} / \mathrm{s}$.

tween drift and wind whereas undrogued buoys move in wind direction with $2-3 \%$ of the wind speed.

\section{Conclusions}

The data from the Atlantic support our results from Kiel Bay: undrogued buoys of the type used are strongly influenced by wind and sea. As the resulting drift is nearly hall due to wind and half due to Stokes drift, other buoy types can modify these results only slightly. Elimination of data from undrogued buoys therefore becomes essential in order to use a data set for detailed analysis. Otherwise, only the first few months should be used, as was done by Krauss and Böning [1987]. Even in areas of very strong currents like the Gulf Stream or Gulf Stream extension area, severe storms yield deviations from the real velocities, which cannot be neglected. The performance of drogued buoys of the configuration described in section 2 is good. The results of the previous section show no correlation with the wind in the subtropical gyre and only a slight dependence on wind speed during heavy winter storms west of Ireland. This can be quantified on the base of our force measurements.

The combined drag of wind and Stokes drift on buoys must follow a quadratic law,

$$
K_{\Sigma}=a W^{2}
$$

because in the undrogued case the balance of (19) with the frictional force (equation $(6 a)$ ), $K_{W}=350 v^{2}$ (undrogued,
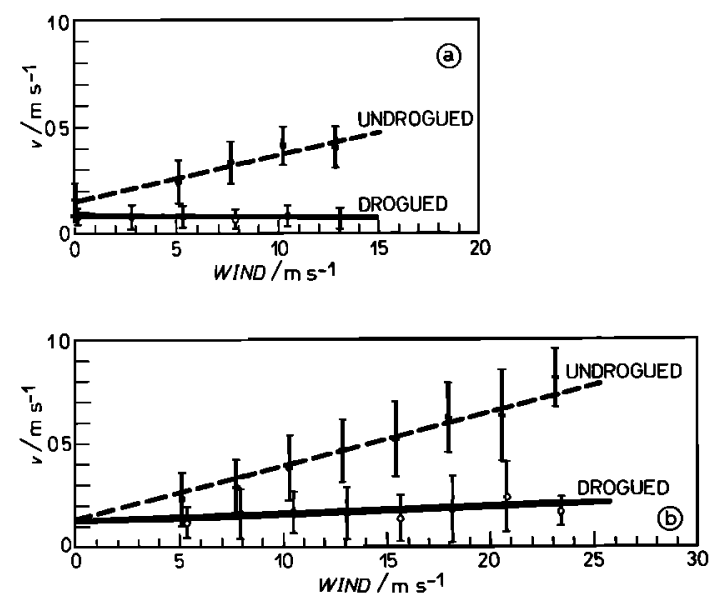

Fig. 11. Drift velocities as function of wind speed (both in meters per second) for drogued (solid line) and undrogued (dashed line) buoys $(a)$ in the subtropical North Allantic and $(b)$ West of Ireland. (Drogued buoys have been shifted by $0.2 \mathrm{~m} / \mathrm{s}$ to the right in order to distinguish them from the undrogued ones in the figure). therefore without weight), must yield the linear relation $v=0.023 \mathrm{~W}$, where the average value of the two data sets has been used as factor. Substituting $v$ into the relation for $K_{W}$ and setting it equal to (19) yields $a=0.18$. The drogued buoy is less exposed to both the wind (deeper submersion) and the Stokes drift (exponential decrease with depth). If we use the same value of 0.18 for drogued buoys, the drag from wind and waves is overestimated. This will give us an upper limit for the slippage of the system.

Let $K_{R}$ be the force on the rope due to currents. If we use a drag coefficient of 1.2 (infinitely long cylinder) and assume a quadratic law, the drag exerted on the rope (100-m length, 1.4-cm diameter) is given by

$$
K_{R}=860 v^{2}
$$

We consider two cases.

Case 1: Wind slippage $\Delta v$ of the system. The balance of forces is given by

$$
K_{\Sigma}=K_{W}+K_{R}+K_{D}
$$

with the forces $K_{i}$ according to $(6 b),(7 a)$ or (7b), (19), and (20). This yields

$$
\begin{gathered}
\Delta v=-0.866+\left(0.866^{2}+1.208 \times 10^{-4} W^{2}\right)^{1 / 2} \\
\Delta v=2.34 \times 10^{-3} W
\end{gathered}
$$

depending on whether $(7 a)$ or $(7 b)$ is used

The result based on a linear drogue force is shown in Figure 12 (solid line), for the quadratic law the dotted curve holds. For a wind of $15 \mathrm{~m} / \mathrm{s}$ we obtain a slippage of $1.5 \mathrm{~cm} / \mathrm{s}$ as upper limit according to our choice of $a$ in (19). The quadratic

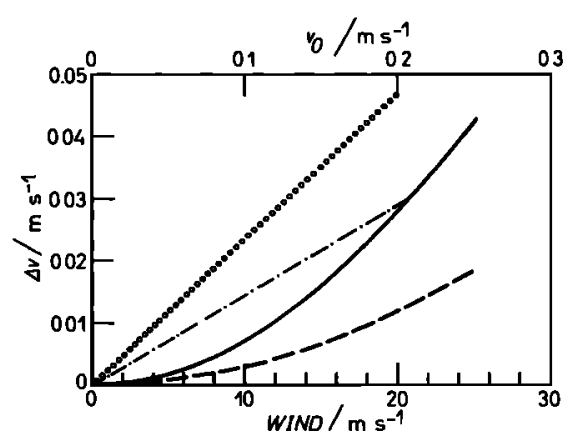

Fig. 12. Theoretical slippage $\Delta v$ (in meters per second) of the drogue due to wind and wave action (bottom) scale) and currents in the mixed layer (top scale): solid line, case 1 with linear drogue force; dotted line, case 1 with quadratic drogue force; dashed line case 2 with linear drogue force; dashed-dotted line, case 2 with quadratic drogue force. 
law would result in $3.5 \mathrm{~cm} / \mathrm{s}$, which contradicts Figure $11 a$. The mean wave height under these conditions amounts to 4.5 $\mathrm{m}$, and the mean height of the 10 highest out of 100 consecutive waves is $8.8 \mathrm{~m}$. If the rope stretches by $5 \%(5 \mathrm{~m})$, the buoy will already become submerged under the wave crest, which further reduces the direct wind influence. This holds even more for higher wind speeds. We therefore believe that wind slippage is less than $2 \mathrm{~cm} / \mathrm{s}$ under all conditions.

Case 2: Currents in the mixed layer. With a Coriolis parameter $f=10^{-4} \mathrm{~s}^{-1}$ and a drag coefficient of $1.2 \times 10^{-3}$ for wind stress, Ekman currents averaged over 30-m depth are given by the relation $\bar{v}=4.77 \times 10^{-4} W^{2}(\mathrm{~m} / \mathrm{s})$. Corresponding values are $0.05,0.11$, and $0.30 \mathrm{~m} / \mathrm{s}$ for wind speeds of 5,15 , and $25 \mathrm{~m} / \mathrm{s}$. We replace the Ekman spiral by a constant current $v_{0}$ in the upper $30 \mathrm{~m}$ (according to the mean Ekman values). Then a drag acts on the buoy and the upper $30 \mathrm{~m}$ of the rope and tends to move the system against the resistance of the remaining rope and the drogue. The force balance is given by

$$
K_{W}+0.3 K_{R}^{(1)}=0.7 K_{R}^{(2)}+K_{D}
$$

yielding a slippage

$$
\Delta v=a-\left(a^{2}-3.105 v_{0}^{2}\right)^{1 / 2} \quad a=4.511+3.077 v_{0}
$$

Here, $K_{R}{ }^{(1)} \sim\left(v_{0}-\Delta v\right)^{2}$, and $K_{R}{ }^{(2)} \sim(\Delta v)^{2}$.

This is depicted in Figure 12 as a dashed line for the linear drogue force. The slippage is less than $2 \mathrm{~cm} / \mathrm{s}$, which may again be considered to be an upper limit because if the Ekman vector were used, part of the forces would cancel each other. If the quadratic drogue force is applied, we have

$$
\Delta v=0.143 v_{0}
$$

which gives the dashed-dotted line in Figure 12. Again, this slippage contradicts the observations depicted in Figure 11a, which are completely uncorrelated with the wind. We thus come to the conclusion that even under gale conditions the slippage is less than $2 \mathrm{~cm} / \mathrm{s}$ for each of the two cases and can be tolerated. Under average conditions, we have wind speeds of less than $9 \mathrm{~m} / \mathrm{s}$ in the northern North Atlantic during summer and less than $13 \mathrm{~m} / \mathrm{s}$ during winter [Isemer and Hasse, 1985]. The total slippage in summer should be less than $1 \mathrm{~cm} / \mathrm{s}$ on the average and may range between 1 and 2 $\mathrm{cm} / \mathrm{s}$ in winter. This is to be compared with rms velocities of $20 \mathrm{~cm} / \mathrm{s}$ in the eddy fields [Krauss and Böning, 1987] of that area. At mid-latitudes and in the subtropical gyre, slippage is no problem.

\section{REFERENCES}

Dietrich, G., K. Kalle, W. Krauss, and G. Siedler, General Oceanography, 2nd rev. ed., translated from German by $\mathrm{S}$. Roll and $\mathrm{H}$. U. Roll, 626 pp., Wiley-Interscience, New York, 1980.

Isemer, H.-J., and L. Hasse, The Bunker Climate Atlas of the North
Atlantic Ocean, vol. 1, Observations, 218 pp., Springer-Verlag, New York, 1985.

Kırwan, A. D., Jr., G. McNally, M.-S. Chang, and R. Molinari, The effect of wind and surface currents on drifters, J. Phys. Oceanogr., 5 , 361-368, 1975.

Kirwan, A. D., Jr., G. McNally, E. Reyna, and W. J. Merrell, Jr., The nearsurface circulation of the eastern North Pacific, J. Phys. Oceanogr., 8, 937-945, 1978, 1978a.

Kirwan, A. D., Jr., G. McNally, and S. Pazan, Wind drag and relative separation of undrogued drifters, J. Phys. Oceanogr., 8, 1146-1150, $1978 b$.

Kirwan, A. D., Jr., G. McNally, S. Pazan, and R. Wert, Analysis of surface current response to wind, J. Phys. Oceanogr., 9, 401-412, 1979.

Krauss, W., Theorie des Triftstromes und der virtuellen Reibung im Meer, Dtsch. Hydrogr. Z., 18, 193-210, 1965.

Krauss, W., The North Atlantic Current, J. Geophys. Res., 9l(C4), $5061-5074,1986$.

Krauss, W., and C. W. Böning, Lagrangian properties of eddy fields in the northern North Atlantic as deduced from satellite-tracked buoys, J. Mar. Res., 45, 259-291, 1987.

Krauss, W., and R. H. Käse, Mean circulation and eddy kinetic energy in the eastern North Atlantic, J. Geophys. Res., $89(\mathrm{C} 3)$, 3407-3415, 1984.

Lange, $P$., and $H$. Hühnerfuss, Drift response of monomolecular slicks to waves and wind action, J. Phys. Oceanogr., 8, 142-150, 1978.

McNally, G. J., Satellite-tracked buoy observations of the nearsurface flow in the eastern mid-latitude North Pacific, J. Geophys. Res., 86, 8022-8030, 1981.

McNally, G. J., and W. B. White, Wind driven flow in the mixed layer observed by drifting buoys during autumn-winter in the midlatilude North Pacific, J. Phys. Oceanogr., 15, 684-694, 1985.

Niiler, P., R. Davis, and H. J. White, Water-following characteristics of a mixed layer drifter, Deep Sea Res., 34, 1867-1881, 1987.

Richardson, P. L., Gulf Stream trajectories measured with freedrifting buoys, J. Phys. Oceanogr., Il, 999-1010, 1981.

Richardson, P. H., and C. M. Wooding, Surface drifter measurements in the Atlantic North Equatorial Countercurrent 1983-1985, Tech. Rep. 85-31, 117 pp., Woods Hole Oceanogr. Inst., Woods Hole, Mass., 1985.

Stommel, H., Series observations of drift currents in the central North Allantic Ocean, Tellus, 6, 203-214, 1954.

Tomczak, G., Investigations with drift cards to determine the influence of the wind on surface currents, Stud. Oceanogr., 129-139, 1964.

Vachon, W. A., Drifters, in Air-Sea Interaction. Instruments and Methods, edited by F. Dobson et al., pp. 201-218, Plenum, New York, 1980.

Weller, R. A., and D. Halpern, The velocity structure of the upper ocean in the presence of surface forcing and mesoscale oceanic eddies, Philos. Trans. R. Soc. London, Ser. A, 308, 327-340, 1983.

Weller, R. A., J. P. Dean, J. Marra, J. F. Price, E. A. Francis, and D. C. Boardman, Three dimensional flow in the upper ocean, Science, 277, 1552-1556, 1985.

White, W. B., Vertical Reynolds stress divergence in the upper ocean associated with linear wind-driven, near-inertial wave of finite wavelength, J. Phys. Oceanogr., 16, 1190-1203, 1986.

J. Dengg, H.-H. Hinrichsen, and W. Krauss, Institut für Meereskunde an der Universität Kiel, Düsternbrooker Weg 20, D-2300 Kiel 1, Federal Republic of Germany.

(Received July 15, 1988; accepted August 31, 1988.) 